\title{
Oxygen Transport in Biofilm Electrodes for Screening of Toxic Chemicals
}

A biosensor electrode system with unique configuration and a thin layer of immobilized yeast cells, set on the surface of an amperometric oxygen membrane electrode, was developed for rapid screening of toxic chemicals in a variety of pollution and process control applications. Measurement is based on the instantaneous detection of changes in oxygen respiratory activity of biofilm of yeast cells upon exposure to toxic chemicals.

The design of this electrode system, referred to as biofilm electrodes, was based on a mathematical model of oxygen transport in the biofilm and the electrochemical current response. The biofilm, which consists of three sublayers-boundary layer, filter pad, and yeast cell layer-was modeled as a one composite diffusion layer, or three separate layers in series. While the three layer model is more theoretically complete, the one layer model was more reliable and simpler to use.

\author{
David K. Goldblum \\ Steven E. Holodnick \\ Khalil H. Mancy \\ School of Public Health \\ University of Michigan \\ Ann Arbor, Ml 48109 \\ Dale E. Briggs \\ Department of Chemical Engineering \\ University of Michigan \\ Ann Arbor, MI 48105
}

\section{Introduction}

Biological oxygen uptake rates of suspensions of microorganisms have been conveniently determined by using closed-cell (reactor) respirometers, as shown in Figure la. This is based on in-situ monitoring of dissolved oxygen by amperometric membrane electrodes. Since this is a closed system from the atmosphere, the test period is limited by the amount of oxygen in test medium. Once the dissolved oxygen is consumed, respiration rate monitoring will terminate. In certain applications, it is desirable to monitor respiration rates over extended periods of times. This can be achieved by using a reactor open to the atmosphere, as shown in Figure $1 \mathrm{~b}$. Under these conditions, respiration rate monitoring can be extended by replenishing oxygen from the atmosphere (Goldblum, 1988). Further optimization of this system led to the development of the biofilm electrode, shown in Figure Ic, where the microorganisms form a thin layer separating the oxygen electrode from the test solution. The oxygen concentration in the test solution is maintained at equilibrium with the oxygen atmospheric partial pressure. With this configuration, the electrode response indicates the oxygen flux across the biofilm, which under controlled experimental conditions, is solely dependent on the biological oxygen uptake rate.

Electrode systems of this type are referred to in this article as

Current address D. K. Goldblum USAF, Occupational and Environmental Health Laboratory, Brooks AFB, TX 78235 .

Correspondence concerning this paper should be addressed to D. E. Briggs. biofilm electrodes (BFE). The biofilm can be made of enzymes (Davis, 1986; Lowe, 1985; Mancy, 1984), organelles such as mitochondria (Haubenstricker, 1984), bacteria (Holodnick, 1988), yeast, and mammalian cells (Goldblum and Holodnick, 1988).

The BFE system under investigation consists of an amperometric oxygen membrane electrode, also known as a dissolved oxygen electrode (DOE), and a biofilm of immobilized yeast cells. This electrode system shows great commercial potential in both industrial and regulatory applications, largely based on its ability for rapid screening of toxic substances at a great saving in time and expenses. Details of the BFE are illustrated in Figure 2. Oxygen transport in such BFE systems is the physical phenomenon that renders it advantageous as a biosensor. Exposure of the BFE to a toxic chemical changes the respiration rate of the biofilm and consequently the oxygen concentration at the DOE. In this article, mathematical models for oxygen transport through the immobilized biofilm and the BFE diffusion current equation are presented. These models serve as the bases for the optimal design of BFE systems.

\section{Model Description}

The composite biofilm in a BFE is physically viewed as three distinct layers: 1. boundary layer; 2. filter pad (polysulfone pad); and 3. yeast cell layer. The composite biofilm can be modeled as a one-layer volume element, or the volume element can 
(a)

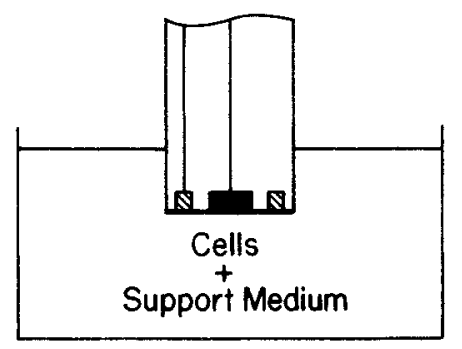

(b)

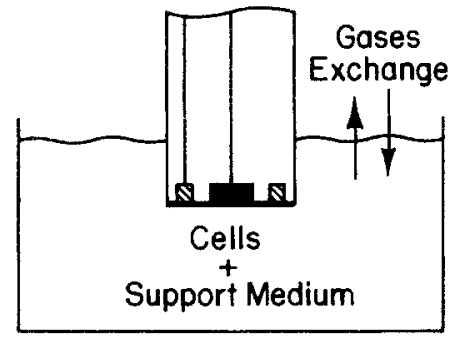

(c)

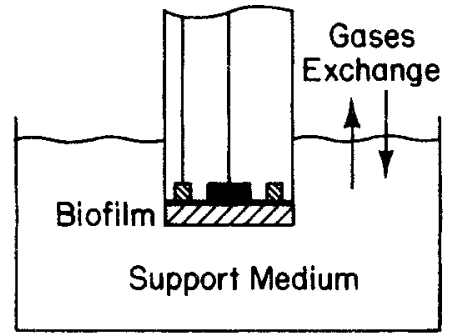

Figure 1. Biosensor systems.

be modeled as three separate layers in series with respiration confined to the cell layer.

The oxygen mass balance on a volume element is used to derive a concentration profile $(C)$ as a function of the diffusion path distance $(z)$ from the bulk solution towards the oxygen sensor, where $z=0$ at the boundary layer/bulk solution interface and $z=b$ at the plastic membrane/yeast cell layer interface. From the concentration $(C)$, the concentration at the plastic membrane/yeast cell layer interface $\left(C_{b}\right)$, i.e., $C$ at $z=b$, is obtained, and cellular respiration rate per unit volume, $k$ is determined.

\section{Model Formulations}

The DOE current output $(i)$ is proportional to the oxygen concentration $\left(C_{b}\right)$ at the plastic membrane interface $(z=b)$ (Mancy et al., 1962).

$$
i=\phi C_{b}
$$

where $\phi$ is the electrode sensitivity coefficient.

$$
\phi=\frac{i_{S}}{C_{S}}
$$

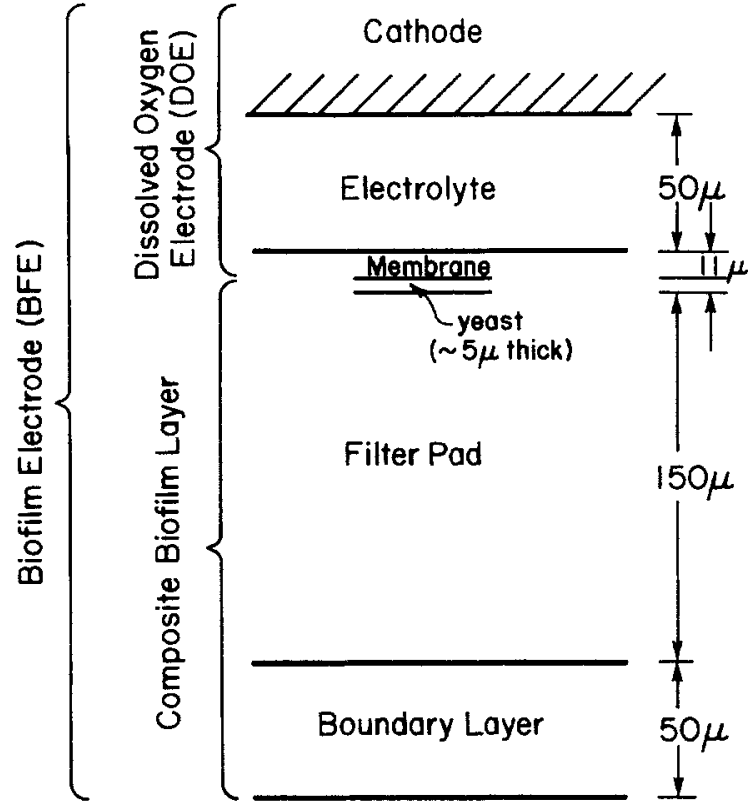

Figure 2. Composite structure of DOE biofilm.

and

$$
\phi=\frac{n F A P_{m}}{L_{p}}
$$

An oxygen mass balance for any volume element contains some or all of the following:

Accumulation $(A C C)=\operatorname{influx}(I)$

$$
\text { - efflux }(E)+\text { generation }(G)
$$

Since the BFE responds rapidly and is essentially in steady state, accumulation vanishes, i.e., $A C C=0$. The influx represents oxygen diffusion into the volume element at $z=z$, whereas efflux represents oxygen diffusion out of the volume element at $z=z+\Delta z$, where the volume's cross-sectional area is that of the working electrode surface $(A)$. Diffusion is governed by Fick's First Law and is assumed to be the sole mechanism of oxygen transport.

The generation term represents the oxygen consumption due to respiration by the yeast cells. Respiration rate per unit volume $(R)$ can be expressed by the Monod Equation (Rittman and McCarty, 1980; Kornegay and Andrews, 1968).

$$
R=-\frac{k N C}{K_{S}+C}
$$

The generation term is negative, since oxygen is consumed by respiration rather than produced. Current output is linearly dependent on the number of cells $(N)$ immobilized and is consistent with the oxygen excess regime $\left(K_{S} \ll C\right)$, the rate being pseudozero order with respect to oxygen concentration. Equation 5 is simplified to

$$
R=-k N
$$




\section{Three-layer model}

The cell layer in the three-diffusion-layer model is comparable to the composite biofilm in the one-layer model. The concentration profiles in the boundary layer and filter pad are linear, since the generation term in the oxygen mass balance is zero. Steady state is assumed so that the accumulation term is zero in all three layers. Hence, the differential equations from respective oxygen mass balances are:

Boundary Layer:

$$
\frac{d^{2} C_{B L}}{d z^{2}}=0
$$

Filter Pad:

$$
\frac{d^{2} C_{f}}{d z^{2}}=0
$$

Cell Layer:

$$
\frac{d^{2} C_{c}}{d z^{2}}=\frac{k N}{D_{c}}
$$

\section{Boundary Conditions:}

At $z=0, C=C_{B L}=C_{S}$

At $z=\delta$, the continuity of concentration and flux at boundary layer/filter pad interface results in $C=C_{B L}=C_{f}=C_{f l}$, so that

$$
-\left.D_{f} \frac{d C_{f}}{d z}\right|_{z=\delta}=-\left.D_{W} \frac{d C_{B L}}{d z}\right|_{z=\delta}
$$

At $z=\delta+L_{j}$, the continuity of concentration and flux at filter pad/cell layer interface results in $C=C_{f}=C_{c}=C_{f 2}$ so that

$$
-\left.D_{c} \frac{d C_{c}}{d z}\right|_{z=\delta+L_{j}}=-\left.D_{f} \frac{d C_{f}}{d z}\right|_{z=\delta+L_{f}}
$$

At $z=b$, the flux at cell layer/plastic membrane interface results in

$$
\begin{aligned}
-\left.D_{c} \frac{d C_{c}}{d z}\right|_{z-b}=i /(n F A)=\phi C_{b} /(n F A) & \\
& =\left(\frac{n F A P_{m}}{L_{p}}\right) \frac{C_{b}}{n F A}=\frac{P_{m} C_{b}}{L_{p}}
\end{aligned}
$$

leading to

$$
\left.\frac{d C_{c}}{d z}\right|_{z-b}=-\frac{P_{m} C_{b}}{L_{p} D_{c}}
$$

where $b=\delta+L_{f}+L_{c}=$ thickness of composite biofilm Concentration Profiles:

(a) Boundary Layer

$$
C=C_{B L}=C_{S}-\frac{P_{m} C_{k}}{L_{p} D_{W}} z
$$

(b) Filter Pad

$$
C=C_{f}=C_{S}-\frac{P_{m} C_{k}}{L_{p}}\left(\frac{\delta}{D_{W}}+\frac{z-\delta}{D_{f}}\right)
$$

(c) Cell Layer

$$
\begin{aligned}
C=C_{c}=C_{S}-\frac{P_{m}}{L_{p}}\left[C_{k}\left(\frac{\delta}{D_{W}}+\frac{L_{f}}{D_{f}}\right)\right. & \left.+C_{b}\left(\frac{z-\delta-L_{f}}{D_{c}}\right)\right] \\
& -\frac{k N}{2 D_{c}}\left[L_{c}^{2}-(z-b)^{2}\right]
\end{aligned}
$$

Interface Concentrations:

(a) Boundary Layer/Filter Pad

$$
C_{f 1}=C_{S}-\frac{P_{m} C_{k}}{L_{p} D_{w}} \delta
$$

(b) Filter Pad/Cell Layer

$$
C_{f 2}=C_{S}-\frac{P_{m} C_{k}}{L_{p}}\left(\frac{\delta}{D_{W}}+\frac{L_{f}}{D_{f}}\right)
$$

(c) Cell Layer/DOE Plastic Membrane

$$
C_{b}=\frac{C_{S}-\frac{P_{m} C_{k}}{L_{p}}\left(\frac{\delta}{D_{w}}+\frac{L_{f}}{D_{f}}\right)-\frac{k N L_{c}^{2}}{2 D_{c}}}{1+\frac{P_{m} L_{c}}{L_{p} D_{c}}}
$$

Solving for $k$, Eq. 19 is obtained

$$
k=\frac{2 D_{c}}{N L_{c}^{2}}\left[C_{S}-\frac{P_{m} C_{k}}{L_{p}}\left(\frac{\delta}{D_{W}}+\frac{L_{f}}{D_{f}}\right)-C_{b}\left(1+\frac{P_{m} L_{c}}{L_{p} D_{c}}\right)\right]
$$

From the three-layer model, $k$ can alternatively be estimated from the boundary condition stated in Eq. 11 , i.e., continuity of flux at the filter pad/cell layer interface. Hence, from Eqs. 11, 14 and $15, k$ can be represented as

$$
k=\frac{P_{m}}{L_{p}}\left(\frac{C_{k}-C_{b}}{N L_{c}}\right)=\frac{i_{k}-i_{b}}{n F A N L_{c}}
$$

where

$i_{b}=$ steady-state current; $i_{s s}$ for the control runs and $i_{f}$ for the test runs, $\mathrm{A}$ or $\mu \mathrm{A}$

Derivation of $k$ from the boundary condition stated in Eq. 11 is discussed by Goldblum (1988).

\section{One-layer model}

In the one-layer model, Eqs. 9 and 12, apply to the entire biofilm, which is considered as one homogenous diffusion layer. In these equations, $C_{c}$ is replaced by $C$ and $D_{c}$ by $D$ to give Eqs. 21 and 22. The mass balance thus becomes:

$$
\frac{d^{2} C}{d z^{2}}=\frac{k N}{D}
$$

Equation 21 is a simple second-order differential equation subject to the following boundary conditions:

$$
\begin{aligned}
& \text { At } z=0, C=C_{S} \\
& \text { At } z=b, \text { Flux }=i /(n F A)=-D d C /\left.d z\right|_{z-b}
\end{aligned}
$$


From Eqs. 1 and 3,

$$
\left.\frac{d C}{d z}\right|_{z=b}=-\frac{P_{m} C_{b}}{L_{p} D}
$$

Solving for $C$ :

$$
C=C_{S}-\frac{P_{m} C_{b}}{L_{p} D} z-\frac{k N z}{2 D}(2 b-z)
$$

At $z=b, C=C_{b}$ and

$$
C_{b}=\frac{C_{S}-\frac{k N b^{2}}{2 D}}{1+\frac{P_{m} b}{L_{p} D}}
$$

The oxygen concentration $C_{b}$ is observed from the steady-state current so that the cellular respiration rate, $k$ can be computed from Eq. 24,

$$
k=\frac{2 D}{N b^{2}}\left[C_{S}-C_{b}\left(1+\frac{P_{m} b}{L_{p} D}\right)\right]
$$

\section{Determination of Parameters for Models}

The oxygen concentration in the bulk solution at saturation, $C_{S}$, is obtained from $\mathrm{O}_{2}$ solubility charts at a given temperature and pressure (Hitchman, 1978), and the cell number, $N$, is determined with a hemocytometer. In the diffusion models presented, only the ratio $P_{m} / L_{p}$ needs to be evaluated. From $i_{S}$ and $C_{S}$, the electrode sensitivity coefficient is computed, using Eq. 2 and $P_{m} / L_{P}$ is obtained from Eq. 3. The parameters $b$ and $D$ are evaluated experimentally via diffusion studies. The cellular respiration rate per unit volume, $k$ must be evaluated, but is strongly coupled with the respiration experiments so that it must be handled differently from the other parameters.

\section{Permeability of plastic membrane}

The thickness of the plastic membrane $L_{p}$ was $0.00109 \mathrm{~cm}$ and was measured using a micrometer under a light microscope. The plastic membrane thickness showed a $\mathrm{COV}$ of $4.19 \%$ over 20 measurements. The measured surface area of the electrode was $1.327 \mathrm{~cm}^{2}$. Over 37 data runs, the average ratio $P_{m} / L_{p}$ was $8.615 \times 10^{-5} \mathrm{~cm} / \mathrm{s},\left(C O V=19.1 \%, 95 \% C I=12.8 \%\right.$ mean $\left.P_{m}\right)$ $\left.L_{p}\right)$. The observed permeability coefficient $\left(P_{m}\right)$ for this plastic membrane (Reynold's plastic polyvinyl chloride film) was $9.357 \times 10^{-8} \mathrm{~cm}^{2} / \mathrm{s}$.

\section{Thickness of composite biofilm}

The thickness of the filter pad was $150 \mu \mathrm{m}$. The mean yeast cell dimensions were obtained from 50 measurements using an optical digitizer under oil immersion microscopy. The short and long dimensions (mean \pm 1 std. dev.) were $4.56 \pm 0.71$ and $5.49 \pm 0.64 \mu \mathrm{m}$, respectively, which agrees well with results obtained by Benefield and Molz (1985). Based on the number $\left(\sim 3 \times 10^{6}\right)$ and estimated volume $\left(6.56 \times 10^{-11} \mathrm{~cm}^{3} / \mathrm{cell}\right)$ of individual cells, the yeast should be deposited on the filter pad in a single layer with a voidage of approximately $70 \%$. Virtually all filtered cells are retained as the filter pad has an effective pore size of $0.45 \mu \mathrm{m}$.

The boundary layer thickness was estimated by comparing the current readout of the DOE and BFE with no cells at stir rates of $340 \mathrm{rpm}$ and $440 \mathrm{rpm}$. The current changed with rpm, but leveled off by $440 \mathrm{rpm}$. It is assumed that the boundary layer is negligible at the higher stir rate so that the current readout is indicative of the saturation current. The lower stir rate yields less current than the higher stir rate, due to an increased boundary layer thickness. Thus, the oxygen concentration at the plastic membrane interface with the filter pad is going to be slightly less at $340 \mathrm{rpm}$. Using Fick's First Law and equating the oxygen diffusivity in the boundary layer to that in water, the boundary layer thickness can be estimated from

$$
\text { Flux }=\frac{i}{n F A}=-\left.D_{W} \frac{d C}{d z}\right|_{\text {interface }}=-D_{W} \frac{\Delta C_{B L}}{\delta}
$$

where

$i=$ steady-state current at low stir rate, A

$\Delta C_{B L}=$ oxygen concentration difference across the boundary layer (proportional to the difference in current between the high and low stir rates), $\mathrm{mol} / \mathrm{cm}^{3}$

$D_{W}=$ diffusivity of $\mathrm{O}_{2}$ in aqueous media, $\mathrm{cm}^{2} / \mathrm{s}$

$D_{W}$ is taken to be $2.84 \times 10^{-5} \mathrm{~cm}^{2} / \mathrm{s}$, in which $D_{W}$ at $25^{\circ} \mathrm{C}$ is $2.5 \times 10^{-5} \mathrm{~cm}^{2} / \mathrm{s}$ (Perry and Chilton, 1973) so that the WilkeChang empirical relation, a modification of the Stoke-Einstein relation (Bird et al., 1960; Perry and Chilton, 1973; Reid et al., 1977 ) is used to correct for the temperature from $25^{\circ} \mathrm{C}$ to $30^{\circ} \mathrm{C}$ (the test media temperature). Ten estimates of the boundary layer thickness resulted in a mean $\delta=50 \mu \mathrm{m}$ with a $C O V$ of $35 \%$. Estimates of the boundary layer thickness ranged from 27 to $83 \mu \mathrm{m}$, the $95 \% \mathrm{Cl}$ being about $1 / 4$ the magnitude of the mean $\delta$. Thus, the thickness of the composite biofilm can be considered to be $205 \mu \mathrm{m}$.

\section{Oxygen diffusivity}

The overall $\mathrm{O}_{2}$ diffusivity for the composite biofilm layer was measured at the end of each run by completely inhibiting the yeast respiration (killing) with $100 \mathrm{ppm} \mathrm{KCN}$. Using Fick's First Law for the composite layer,

$$
\text { Flux }=\frac{i_{k}}{n F A}=-\left.D \frac{d C}{d z}\right|_{\text {interface }}=-D \frac{\Delta C}{b}
$$

where

$\Delta C=C_{k}-C_{S}=\mathrm{O}_{2}$ concentration gradient across the comSince posite biofilm after kill-off

$$
C_{k}=\left(i_{k} / i_{S}\right) C_{S}
$$

and $C_{b}=C_{k}$ when $k=0$, i.e., no respiration, then

$$
C_{k}=\frac{C_{S}}{1+\left(P_{m} b / L_{p} D\right)}
$$

From an average of 40 data runs, a mean diffusivity of $3.17 \times$ 
$10^{-6} \mathrm{~cm}^{2} / \mathrm{s}$ was obtained in which the COV was $39.7 \%$, and the $95 \% \mathrm{CI}$ about $13 \%$ of the mean value of $D$.

The $\mathrm{O}_{2}$ diffusivity in the filter pad is measured independently by comparing the current output of a DOE with and without a filter pad at the high stir rate. From the measured flux, concentration difference, and the filter pad thickness $\left(L_{f}\right)$, one can solve for the $\mathrm{O}_{2}$ diffusivity in the filter pad $\left(D_{f}\right)$ by Fick's First Law (analogous to Eqs. 26 and 27).

$$
\text { Flux }=\frac{i}{n F A}=-\left.D_{f} \frac{d C}{d z}\right|_{\text {interface }}=-D_{f} \frac{\Delta C}{L_{f}}
$$

where

$i=$ steady-state current with the filter pad at high stir rate, A

$\Delta C=$ oxygen concentration difference from the bulk solution to the plastic membrane interface, i.e., across the filter pad, $\mathrm{mol} / \mathrm{cm}^{3}$

$L_{f}=0.015 \mathrm{~cm}(150 \mu \mathrm{m})$ and $D_{f}=2.879 \times 10^{-6} \mathrm{~cm}^{2} / \mathrm{s}(n=7$, $22.7 \%$ COV).

There was no independent means of measuring the $\mathrm{O}_{2}$ diffusivity of the cell layer $\left(D_{c}\right)$ or its thickness $\left(L_{c}\right)$. Thus, it was obtained by considering the difference between the total diffusion (mass transfer) resistance $(b / D)$ and the sum of the boundary layer and filter pad diffusion resistances $\left(\delta / D_{W}+L_{f} / D_{f}\right)$. Since the three layers are diffusion resistances in series so that the individual resistances add up to the total diffusion resistance of the composite biofilm $(b / D)$.

$$
L_{c} / D_{c}=b / D-\delta / D_{w}-L_{f} / D_{f}
$$

where $L_{c} / D_{c}$ was computed for each run by Eq. 31 .

Thus,

$$
D=\frac{b}{\frac{L_{c}}{D_{c}}+\frac{L_{f}}{D_{f}}+\frac{\delta}{D_{w}}}
$$

so that

$$
D_{c}=\frac{L_{c}}{\frac{b}{D}-\frac{L_{f}}{D_{f}}-\frac{\delta}{D_{w}}}
$$

Diffusivities obtained for $L_{c}=5 \mu \mathrm{m}$ were: $D=3.170 \times$ $10^{-6} \mathrm{~cm}^{2} / \mathrm{s}$ and $D_{c}=4.626 \times 10^{-7} \mathrm{~cm}^{2} / \mathrm{s}$. The COV for $L_{c} / D_{c}$ was $135 \%$. The cell layer diffusion resistance can be neglected, since it is small compared to the filter pad diffusion resistance. Thus, uncertainty in the filter pad diffusion resistance can easily overshadow the cell layer resistance. Taking the limit as $L_{c} / D_{c}$ goes to 0 , Eq. 32 reduces to

$$
D=\frac{b}{\frac{L_{f}}{D_{f}}+\frac{\delta}{D_{w}}}
$$

The overall diffusivity, $D$ is calculated to be $3.698 \times 10^{-6} \mathrm{~cm}^{2} / \mathrm{s}$, which agrees with previous three-layer calculations. Hence, $D$ can be taken as $3.698 \times 10^{-6} \mathrm{~cm}^{2} / \mathrm{s}$, since there is no indepen- dent means for obtaining a more definite assessment of $L_{c}$ or $D_{c}$ From this diffusivity, an estimate for $D_{c}$ was obtained for $L_{c}=5$ $\mu \mathrm{m}$, using Eq. 33 , and $D_{c}$ was calculated as being $3.173 \times$ $10^{-6} \mathrm{~cm}^{2} / \mathrm{s}$.

The overall diffusivity for the three-layer model with cell layer diffusion resistance neglected appears to yield a more reasonable estimate of the cell layer diffusivity, since the magnitude of $D_{c}$ more closely agrees with $D_{W}$ and $D_{f}$. However, for the one-layer model, $D$ is computed for each run, and for the three layer model $D_{c}$ is computed for each run. Li et al. (1988) report an overall diffusivity of $2.18 \times 10^{-5} \mathrm{~cm}^{2} / \mathrm{s}$ in a biofilm of kappacarrageenam mounted on a DOE. Presumably, the fibers in the filter pad offer more resistance to $\mathrm{O}_{2}$ mass transfer than the carrageenam gel containing the cells.

\section{Oxygen concentration at plastic membrane interface}

The $C_{b}$ is computed from the $i_{s}$ value and the steady-state current as

$$
C_{b}=\left(i_{s s} / i_{S}\right) C_{S}
$$

This is done for both the control and test data in each run, $k$ being computed from Eqs. 19, 20 and 25 .

\section{Experimental Methods}

Wild strain bakers' yeast (Saccharomyces Cerevisiae, C276 $\mathrm{a} / \alpha$ ) is inoculated in acetate growth media and mixed in a $30^{\circ} \mathrm{C}$ incubator for $36-40$ hours. Haubensticker (1984) shows that yeast cells show the same metabolic activity for incubation periods of 12 to 48 hours, as long as the yeast population is in the exponential (log) growth phase. Therefore, calibration curves, obtained for a given biosensor over time and with different yeast loadings, are the same. Hence, a sensor need not be calibrated with each unknown sample.

Cell growth is halted by placing the culture in an ice-water bath, at which time a cell density is assessed with a hemocytometer (Spencer Bright-line $0.1 \mathrm{~mm}$, American Optical Co.) coupled with a Zeiss microscope $(10 \times$ oc $/ 10 \times$ obj $)$. The growth medium is made up by mixing $18.2-\mathrm{g} \mathrm{Na}$ acetate, $1.15-\mathrm{mL}$ glacial acetic acid, and 14-g of yeast $\mathrm{N}_{2}$ base (Difco Laboratories, Detroit) with sufficient distilled water to make $1 \mathrm{~L}$ of such a growth buffer solution at a final $\mathrm{pH}=5.8$. The cell culture is diluted with $\mathrm{pH} 5.8$ acetate buffer (growth media minus yeast $\mathrm{N}_{2}$ base), and $3-5 \times 10^{6}$ cells $(\sim 3 \mathrm{~mL})$ are suction-filtered over the central $1.1-\mathrm{cm}^{2}$ area of a $0.45-\mu \mathrm{m} \mathrm{GA-6S}$ polysulfone filter membrane having a diameter of $25 \mathrm{~mm}$ (Gelman Science, Ann Arbor). After filtration, the damp filter is inverted onto the head of a galvanic DOE and retained with a cap assembly, yielding a BFE. The BFE is inserted in a chamber containing $55-\mathrm{mL}$ airsaturated acetate assay medium (buffer) stirring at $340 \mathrm{rpm}$ and being maintained at $30^{\circ} \mathrm{C}$. The BFE current output attains $i_{s s}$ in $45-50 \mathrm{~min}$. This $i_{s s}$ current datum is then used to compute an oxygen level at the plastic membrane interface ( $C_{b}$ in Eq. 35) and a respiration rate per cell ( $k$ in Eqs. 19, 20 or 25).

The two chemicals studied were potassium cyanide (KCN), a strong respiratory inhibitor, and 2,4-dinitrophenol (2,4-DNP), a strong respiratory uncoupler (Lehninger, 1975). One $\mathrm{mL}$ of a standard KCN or 2,4-DNP solution (prepared $55 \times$ strength) is added to the assay medium, for a second steady-state current, $i_{f}$ After this steady state is attained, $C_{b}$ from Eqs. 1 and 2 and $k$ for 
the test are obtained. At this point, $100-\mathrm{ppm} \mathrm{KCN}$ is added to completely inhibit respiration, thus giving the kill-off current $\left(i_{k}\right)$ and $C_{k}$ (see Eqs. 1, 2 and 28).

For these experiments, $k$ obtained before the chemical is added (control) is compared to that obtained after the toxic chemical is added at a given concentration (test). Cellular respiration rate per unit volume, $k$, given by the Monod Equation is affected by system volume. It is expected that the respiration rate for the entire biofilm $(\mathrm{kN})$ will show less variation than $k$, since it is not subject to errors inherent in the cell counting procedure (see Eqs. 19, 20 and/or 25).

\section{Results and Discussion}

The respiratory control ratio ( $\mathrm{RCR}$ ) for a single cell and the total cell population is given as

$$
\begin{gathered}
\mathrm{RCR}_{k}=\frac{k_{\text {test }}}{k_{\text {con }}} \times 100 \% \\
\mathrm{RCR}_{k N}=\frac{k N_{\text {test }}}{k N_{\text {con }}} \times 100 \%
\end{gathered}
$$

Since the number of cells $(N)$ alive or dead is the same for the control and test data for a given run, $\mathrm{RCR}_{k}=\mathrm{RCR}_{k N}=\mathrm{RCR}$.

When the RCR is evaluated based on $k$ calculated from the one layer model (Eq. 25), the three-layer model (Eq. 19), or the boundary condition at the filter pad/cell layer interface (Eq. 20), the expression for RCR simplifies to

$$
\mathrm{RCR}=\frac{\left(i_{k}-i_{f}\right)}{\left(i_{k}-i_{s s}\right)}
$$

Thus, RCR is the same regardless of which model is used to compute $k$. For further elaboration of this, see Goldblum (1988).

Furthermore, RCR is independent of all parameters other than respiration rate: i.e., plastic membrane properties $\left(P_{m}\right.$ and $L_{p}$ ), composite biofilm properties ( $D$ and $b$ ), and cell layer properties $\left(D_{c}\right.$ and $\left.L_{c}\right)$. This is readily seen when Eq. 1 is used to represent $R C R$ as

$$
\mathrm{RCR}=\frac{\left(C_{k}-C_{b}\right)_{\text {lest }}}{\left(C_{k}-C_{b}\right)_{\text {control }}}
$$

since $i_{k}=\phi C_{k}$ (Eq. 28), $i_{f}=\phi C_{b} \mid$ test, and $i_{s s}=\phi C_{b} \mid$ control. Note, $\left(C_{k}-C_{b}\right)_{\text {eest }}=C_{k}-C_{b} \mid$ test and $\left(C_{k}-C_{b}\right)_{\text {control }}=C_{k}-$ $C_{b} \mid$ control, since $C_{k}$ is at the same oxygen level at the cell layerplastic membrane interface after the biofilm is killed off with 100 ppm KCN.

For the one-layer model, it follows from Eqs. 24 and 29 that

$$
\left(C_{k}-C_{b}\right)=\frac{k N b^{2}}{2 D}
$$

so that the $b^{2} / 2 D$ will cancel out in the ratio of the test value for $\left(C_{k}-C_{b}\right)$ to the control value for $\left(C_{k}-C_{b}\right)$. For the threelayer model it follows from Eqs. 18, 29 and 31 that

$$
\left(C_{k}-C_{b}\right)=\frac{k N L_{c}^{2}}{2 D_{c}}
$$

Table 1. Effect of KCN: $n=4$

\begin{tabular}{ccc}
\hline$[\mathrm{KCN}], \mathrm{ppm}$ & $\mathrm{RCR}$ & $\mathrm{COV}$ \\
\hline 0.01 & $98.0 \pm 2.0$ & 2.08 \\
0.10 & $80.9 \pm 2.3$ & 2.80 \\
1.00 & $33.1 \pm 2.8$ & 8.35 \\
\hline
\end{tabular}

The RCR values are reported as a mean $\pm 1 \mathrm{SD}$, with the COV expressed as a percentage. Square brackets denote chemical concentration.

so that the $L_{c}^{2} / 2 D_{c}$ will cancel out in the test to control ratio for $\left(C_{k}-C_{b}\right)$. Analogously, for the modified three-layer model from the boundary condition at the cell layer-filter pad interface, it follows from Eq. 20 that

$$
\left(C_{k}-C_{b}\right)=\frac{k N L_{c} L_{p}}{P_{m}}
$$

so that the $L_{c} L_{p} / P_{m}$ will cancel out in the test to control ratio for $\left(C_{k}-C_{b}\right)$. As expected, this was true for all three models consistent with RCR being the same expression for the three models.

Moreover, this RCR value is independent of all other nonrespiratory parameters, since the same electrode is always used for both the control and test data for a given run. It is also true that the number of cells $N$ is the same for the control and test data, as previously mentioned.

\section{KCN Results}

Three $\mathrm{KCN}$ concentrations $(0.01,0.1$ and $1.0 \mathrm{ppm})$ were tested in quadruplicate using cells from a single culture. The results are shown in Table 1.

There was a high degree of correlation between RCR and $\mathrm{KCN}$ concentration, the correlation coefficient, $r=-0.9848$ (Figure 3). The linear regression of the dose response curve was obtained, using the mean RCR. The best fit curve can be expressed as

$$
\mathrm{RCR}=93.05-60.46[\mathrm{KCN}]
$$

This relation indicates a $60 \%$ reduction in respiration per ppm $(\mathrm{mg} / \mathrm{L})$ change in $\mathrm{KCN}$ concentration. The limit of detection is between 0.01 and $0.1 \mathrm{ppm}(\mathrm{mg} / \mathrm{L}) \mathrm{KCN}$ (see Figure 3 ).

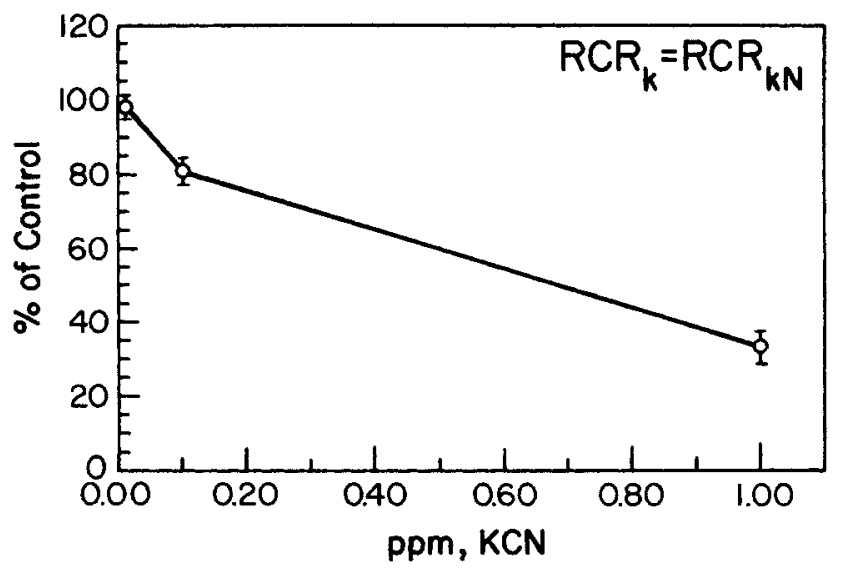

Figure 3. RCR (\% of control) vs. KCN concentration. 
Table 2. Effect of 2,4-DNP: $n=4$

\begin{tabular}{ccc}
\hline [2,4-DPN], ppm & RCR & COV \\
\hline 7 & $102.2 \pm 2.2$ & 2.17 \\
14 & $102.1 \pm 1.0$ & 0.99 \\
28 & $103.5 \pm 1.8$ & 1.69 \\
42 & $104.9 \pm 0.7$ & 0.69 \\
\hline
\end{tabular}

The RCR values are reported as a mean $\pm 1 \mathrm{SD}$, with the COV being expressed as a percentage. Square brackets denote chemical concentration.

\section{2,4-DNP Results}

2,4-DNP was evaluated at four concentrations $(7,14,28$ and $42 \mathrm{ppm}$ ) in quadruplicate using cells from a single culture. The results are presented in Table 2 .

The RCR correlated well with the concentration of 2,4-DNP, $r=0.9727$ (Figure 4). A linear least squares regression analysis yields the following expression:

$$
\mathrm{RCR}=101.28+0.08354[2,4-\mathrm{DNP}]
$$

For the 2.4-DNP analysis, there was a $3-4 \%$ increase in respiration with approximately $40 \mathrm{ppm}(\mathrm{mg} / \mathrm{L})$ 2,4-DNP. Thus, 2,4DNP stimulates respiration at the tested concentrations greater than $15 \mathrm{ppm}$.

\section{One-layer model}

Limits of detection were further analyzed for each chemical discussed according to paired $t$-tests between $k$ values for the control and test sets. Paired $t$-tests on $k$ and $k N$ were carried out where the KCN sets were individually compared with the respective control set ( 3 degrees of freedom, since $n=4$ ).

\begin{tabular}{cc}
\hline Control vs. Test & \multicolumn{1}{c}{$t_{3}$} \\
\hline $0.01 \mathrm{ppm} \mathrm{KCN}$ & $1.7057(p>0.1)$ \\
$0.10 \mathrm{ppm} \mathrm{KCN}$ & $3.4486(p<0.05)$ \\
$1.00 \mathrm{ppm} \mathrm{KCN}$ & $4.6034(p<0.02)$ \\
\hline
\end{tabular}

Thus, the limit of detection was approximately $0.05-0.08$ ppm KCN, since the $0.01 \mathrm{ppm} K C N$ set was slightly below the significance cutoff, and 0.1 and $1.0 \mathrm{ppm} \mathrm{KCN}$ were clearly above the limit of detection. Furthermore, paired $t$-tests were done comparing the control sets for all three $\mathrm{KCN}$ concentra-

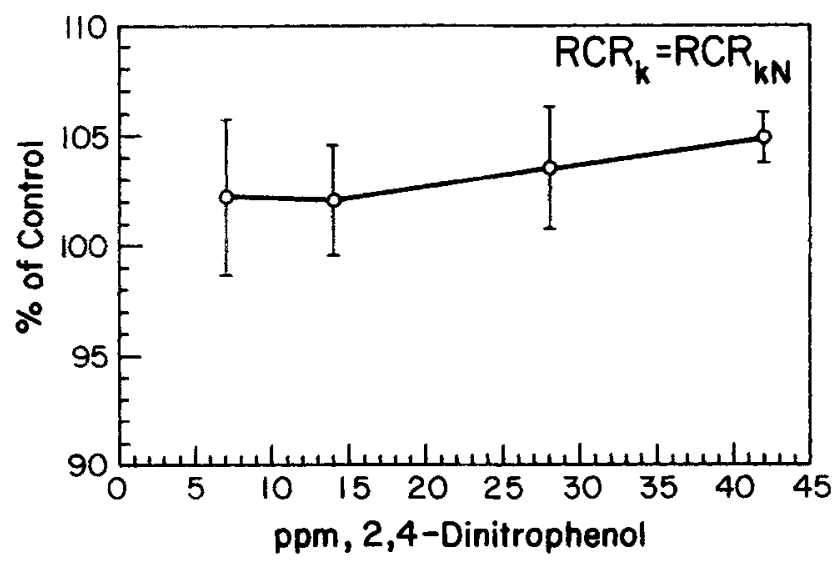

Figure 4. RCR (\% of control) vs. 2,4-DNP concentration. tions. There were no significant differences among any of the control sets indicating that statistical differences can be attributed to the effect of KCN on yeast cell respiration.

Paired $t$-tests were done comparing the individual 2,4-DNP test and control sets, ( 3 degrees of freedom, since $n=4$ ).

\begin{aligned} & \hline Control vs. Test \multicolumn{1}{c}{$t_{3}$} \\ & \hline 7 ppm 2,4-DNP $-3.0928(p>0.05$, borderline $) \\ & 14$ ppm 2,4-DNP $-1.1526(p>0.2) \\ & 28$ ppm 2,4-DNP $-5.9295(p<0.01) \\ & 42$ ppm 2,4-DNP $-4.8315(p<0.02) \\ &$\hline\end{aligned}

The limit of detection was approximately $10-20$ ppm 2,4DNP, since both $28 \mathrm{ppm}$ and $42 \mathrm{ppm}$ were clearly above the limit of detection, whereas $14 \mathrm{ppm}$ was below the limit of detection and $7 \mathrm{ppm}$ was borderline. Paired $t$-tests among the different control sets showed no significant differences so that all the statistical differences can be attributed to the different 2,4 DNP concentrations.

\section{Three-layer model}

Paired $t$-test scores for the $k$ values will now be shown for the three-layer model ( $k$ computed by Eq. 19) as well as for the analysis based on the boundary condition at the filter pad/cell layer interface ( $k$ computed by Eq. 20 ).

For the KCN series, the following $t$-scores were obtained, where the $\mathrm{KCN}$ sets were individually paired with their respective control set ( 3 degrees of freedom, $n=4$ ). The paired $t$-test on $k$ computed from Eq. 19 (three-layer model) shows the following:

\begin{tabular}{cc}
\hline Control vs. Test & $t_{3}$ \\
\hline $0.01 \mathrm{ppm} \mathrm{KCN}$ & $0.2588(p>0.8)$ \\
$0.10 \mathrm{ppm} \mathrm{KCN}$ & $1.1387(p>0.2)$ \\
$1.00 \mathrm{ppm} \mathrm{KCN}$ & $1.3373(p>0.2)$ \\
\hline
\end{tabular}

The paired $t$-test on $k$ computed from Eq. 20 (filter pad/cell layer interface boundary condition) shows the following:

\begin{tabular}{cc}
\hline Control vs. Test & \multicolumn{1}{c}{$t_{3}$} \\
\hline $0.01 \mathrm{ppm} \mathrm{KCN}$ & $1.8568(p>0.1)$ \\
$0.10 \mathrm{ppm} \mathrm{KCN}$ & $5.5599(p<0.02)$ \\
$1.00 \mathrm{ppm} \mathrm{KCN}$ & $4.8305(p<0.02)$ \\
\hline
\end{tabular}

Based on the Eq. 20 analysis, the limit of detection is $0.05-0.08$ ppm KCN. From the Eq. 19 analysis, the limit of detection is uncertain.

For the 2,4-DNP series, the following $t$-scores were obtained, with the 2,4-DNP sets being paired individually with the respective control set ( 3 degrees of freedom, $n=4$ ).

The paired $t$-test on $k$ computed from Eq. 19 (three-layer model) shows the following:

\begin{tabular}{rc}
\hline Control vs. Test & $t_{3}$ \\
\hline 7 ppm 2,4-DNP & $-3.4672(p<0.05)$ \\
14 ppm 2,4-DNP & $0.8432(p>0.4)$ \\
28 ppm 2,4-DNP & $-3.5865(p<0.05)$ \\
42 ppm 2,4-DNP & $-0.4247(p>0.6)$ \\
\hline
\end{tabular}

The paired $t$-test on $k$ computed from Eq. 20 (filter pad/cell 
Table 3. Variation in the BFE Parameters

\begin{tabular}{lccccc}
\hline Parameter & Mean & Std. & COV,\% & $95 \%$ CI & 95\% Confidence Interval \\
\hline$i_{s}, \mu a m p$ & 10.20 & 1.977 & 19.4 & 0.6591 & $9.544-10.86$ \\
$i_{k}, \mu a m p$ & 6.324 & 1.013 & 16.0 & 0.3378 & $5.986-6.662$ \\
$i_{s s}, \mu a m p$ & 3.777 & 1.264 & 33.5 & 0.4215 & $3.356-4.199$ \\
$C_{S}, m g / L$ & 7.397 & 0.04426 & 0.598 & 0.01476 & $7.3822-7.4118$ \\
$C_{k}, m g / L$ & 4.661 & 0.6849 & 14.7 & 0.2284 & $4.4326-4.8894$ \\
$C_{b}, m g / L$ & 2.794 & 0.9563 & 34.2 & 0.3189 & $2.4751-3.1129$ \\
$N, \mathrm{cells}$ & $3.755 \times 10^{6}$ & $6.614 \times 10^{5}$ & 17.6 & $2.205 \times 10^{5}$ & $3.535-3.976 \times 10^{6}$ \\
$P_{m} / L_{p}, \mathrm{~cm} / \mathrm{s}$ & $8.615 \times 10^{-5}$ & $1.649 \times 10^{-5}$ & 19.1 & $5.499 \times 10^{-6}$ & $8.065-9.165 \times 10^{-5}$ \\
$b / D, \mathrm{~s} / \mathrm{cm}$ & 7146.55 & 2377.62 & 33.3 & 792.82 & $6353.73-7393.37$ \\
$L_{d} D_{c}, \mathrm{~s} / \mathrm{cm}$ & 1760.60 & 2377.62 & 135 & 792.82 & $967.78-2553.42$ \\
\hline
\end{tabular}

$95 \% \mathrm{CI}=$ magnitude of the $95 \%$ confidence interval on one side of the mean value.

layer interface boundary condition) shows the following:

\begin{aligned} & \hline Control vs. Test \multicolumn{1}{c}{$t_{3}$} \\ & \hline $7 \mathrm{ppm} 2,4-\mathrm{DNP}-2.8685(0.05<p<0.1$, borderline $) \\ & 14 \mathrm{ppm} \mathrm{2,4-DNP}-1.2285(p>0.2) \\ & 28 \mathrm{ppm} 2,4-$ DNP $-6.9192(p<0.01) \\ & 42 \mathrm{ppm} 2,4-$ DNP $-6.0462(p<0.01) \\ &$\hline\end{aligned}

Based on the Eq. 20 analysis the limit of detection is $10-20 \mathrm{ppm}$ 2,4-DNP. The limit of detection based on the three-layer model is ill defined, ranging from $7-50 \mathrm{ppm}$.

The $t$-scores on the paired $t$-tests are different for the three different analyses on $k$. This becomes clear when the ratios of $k$ computed among the three analyses are considered If

$k_{0}=k$ computed from Eq. 20, the boundary condition concerning flux continuity at the filter pad/cell layer interface in Eq. II

$k_{1}=k$ computed from Eq. 25 , using the one-layer model to estimate the respiration per cell

$k_{3}=k$ computed from Eq. 19 , using the three-layer model to estimate the respiration per cell

then the following ratio expressions are obtained:

$$
\frac{k_{1}}{k_{o}}=\frac{2 C_{S} L_{c}}{b\left(C_{S}-C_{k}\right)}
$$

obtained from Eqs. 1, 2, 3, 19, 20, 27 and 28 .

$$
\frac{k_{3}}{k_{a}}=2\left(1+\frac{D_{c} L_{p}}{L_{c} P_{m}}\right)
$$

obtained from Eqs. 1, 2, 3, 19, 20, 27 and 31 .

$$
\frac{k_{3}}{k_{\mathrm{I}}}=\left(\frac{b}{L_{c}}\right)\left(\frac{C_{S}-C_{k}}{C_{S}}\right)\left(1+\frac{D_{c} L_{p}}{L_{c} P_{m}}\right)
$$

obtained from Eqs. 1, 2, 3, 19, 25, 28 and 31 .

From Eqs. 41,42 and 43 , it becomes clear that the $t$-scores are not going to be the same for the three analyses, since the respective ratios are going to vary between runs. However, in Eq. 41 , the only variable that will vary appreciably between runs is $C_{k}$ so that the $t$-scores for $k_{o}$ and $k_{1}$ agree fairly well, i.e., $k$ computed from Eqs. 20, and 25. Conversely, in Eqs. 42 and 43 the cell layer resistance $\left(L_{c} / D_{c}\right)$ will vary tremendously from run to run. This is the primary source of discrepancy between the $t$-scores of the three-layer model and those of the other two analyses. Furthermore, the $P_{m} / L_{p}$ ratio can vary more than $C_{k}$, but not to the same extent as $L_{c} / D_{c}$.

The variation within the following parameters amongst the data runs is shown in Table 3.

The $t$-scores for the one-layer model (Eq. 25) and the filter pad/cell layer flux continuity analysis (Eqs. 11 and 20) agree quite well. The three-layer model analysis ( $k$ from Eq. 19) showed tremendous variation in the cell layer resistance, seven out of 37 data runs, indicating a negative cell layer resistance. This uncertainty in the cell layer resistance is the primary reason for the $t$-scores being so different from the other two analyses (see Eqs. 42 and 43). This variation in cell layer resistance is due to the filter pad resistance being the dominant diffusion resistance, uncertainty in the filter pad resistance being larger than the magnitude of the cell layer resistance.

The flux continuity at the filter pad/cell layer interface model would seem to correlate most closely with actual respiration rates, since it is calculated from a measured flux difference. Furthermore, it is not subject to the uncertainty of any diffusion resistance. The one-layer model is subject to the uncertainty of the total diffusion resistance, and the overall three-layer model is subject to the uncertainty of the cell layer diffusion resistance.

The three-layer model comes closest to describing the physical system of the BFE. The one-layer model inherently assumes that the yeast cells are uniformly distributed throughout the biofilm: the boundary layer and the filter pad. Since the yeast cell dimensions are $4.5-5.5 \mu \mathrm{m}$, and the pore size of the filter pad is $0.45 \mu \mathrm{m}$, all of the filtered cells remain on the filter pad surface. Hence, the one-layer model is an oversimplification of the actual physical situation, but is quite effective if the total diffusion resistance is used individually for each data run. The value of $k$ based on Eq. 20, the continuity of flux (Eq. 11), is also derived from the more realistic three-layer analysis, but the $k$ computed from Eq. 20 is subject to the uncertainty in cell layer thickness. However, in RCR and paired $t$-test analyses, this uncertainty cancels in the respective ratios, so that for paired $t$-tests, $k$ from Eq. 20 is the most reliable respiratory index. Of course, all three analyses yield the same RCR value. Estimates of $k$ from the one layer model are more reliable approximations of the actual yeast respiration rates, whereas $k$ from Eq. 20 is best for the paired $r$-test analysis, in assessing limits of detection.

The biofilm concentration profiles for the one- and threelayer models are contrasted in Figure 5. For the one-layer mod- 

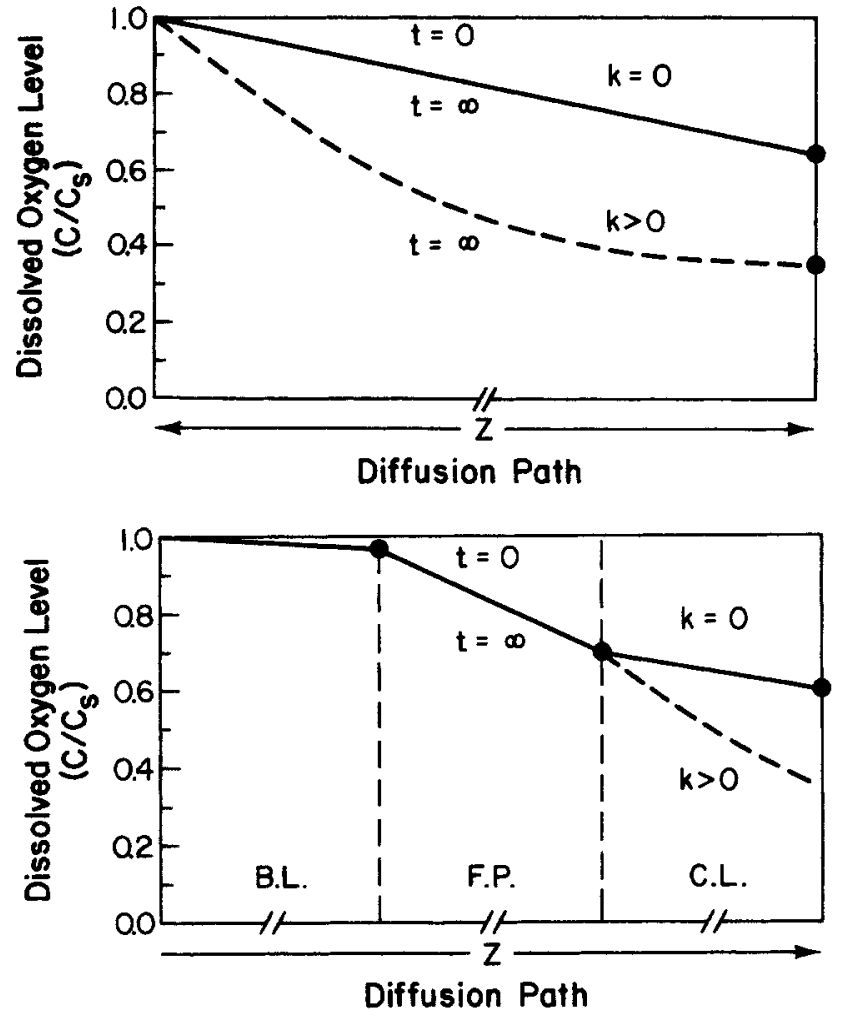

Figure 5. Concentration profiles of the one-(top) and three (bottom)-layer diffusion models.

BL = boundary layer; FP = filter pad; $C L$ = cell layer

el, $C$ is linear with respect to $z$ with a uniform slope when there is no respiration $(k=0)$, and quadratic when there is respiration $(k>0)$. However, for the three-layer model, $C$ is linear with respect to $z$ in both the boundary layer and filter pad regardless of respiratory state, the slopes differing because of different diffusivities in the two layers. In the cell layer of the three-layer model, $C$ is linear when there is no respiration and quadratic when there is respiration.

The mathematical models presented in this article can be used for the optimal design of BFE systems. In this study, experiments were conducted with single toxic substances. In many applications, the test sample may include mixtures of chemicals. Future studies should be directed towards modeling of BFE responses to mixtures of toxic substances of different potencies.

\section{Notation}

$A=$ cross-sectional area of the biofilm, $\mathrm{cm}^{2}$

$b=$ biofilm thickness, $\mathrm{cm}$ or $\mu \mathrm{m}$

$B L=$ boundary layer

$C=\mathrm{O}_{2}$ concentration in the biofilm, $\mathrm{mg} / \mathrm{L}$ or $\mathrm{mol} / \mathrm{cm}^{3}$

$C_{b}=\mathrm{O}_{2}$ concentration in the biofilm at the plastic membrane/cell layer interface, $\mathrm{mg} / \mathrm{L}$ or $\mathrm{mol} / \mathrm{cm}^{3}$

$C_{B L}=\mathrm{O}_{2}$ concentration in the boundary layer, $\mathrm{mg} / \mathrm{L}$ or $\mathrm{mol} / \mathrm{cm}^{3}$

$C_{c}=\mathrm{O}_{2}$ concentration in the cell layer, $\mathrm{mg} / \mathrm{L}$ or $\mathrm{mol} / \mathrm{cm}^{3}$

$C_{f}=\mathrm{O}_{2}$ concentration in the filter pad, $\mathrm{mg} / \mathrm{L}$ or $\mathrm{mol} / \mathrm{cm}^{3}$

$C_{f_{1}}=\mathrm{O}_{2}$ concentration at the boundary layer/filter pad interface, $\mathrm{mg} / \mathrm{L}$ or $\mathrm{mol} / \mathrm{cm}^{3}$

$C_{f 2}=\mathrm{O}_{2}$ concentration at the filter pad/cell layer interface, $\mathrm{mg} / \mathrm{L}$ or $\mathrm{mol} / \mathrm{cm}^{3}$

$C_{k}=\mathrm{O}_{2}$ concentration in the non-viable biofilm at the plastic membrane/cell layer interface, $\mathrm{mg} / \mathrm{L}$ or $\mathrm{mol} / \mathrm{cm}^{3}$
$C_{S}=\mathrm{O}_{2}$ concentration in the biofilm under air-saturation conditions, $\mathrm{mg} / \mathrm{L}$ or $\mathrm{mol} / \mathrm{cm}^{3}$

$C I=$ confidence interval, usually $95 \%$ confidence interval

$C L=$ cell layer

$\mathrm{COV}=$ coefficient of variation $=$ ratio of the standard deviation to the mean, $\%$

$D=$ diffusivity of $\mathrm{O}_{2}$ in the composite biofilm, $\mathrm{cm}^{2} / \mathrm{s}$

$D_{c}=$ diffusivity of $\mathrm{O}_{2}$ in the cell layer, $\mathrm{cm}^{2} / \mathrm{s}$

$D_{f}=$ diffusivity of $\mathrm{O}_{2}$ in the filter pad, $\mathrm{cm}^{2} / \mathrm{s}$

$D_{w}=$ diffusivity of $\mathrm{O}_{2}$ in the boundary layer, taken to be that of aqueous media at the appropriate temperature, $\mathrm{cm}^{2} / \mathrm{s}$

$F=$ Faraday's constant $=96,490 \mathrm{C} /$ equivalent

$\mathrm{FP}=$ filter pad

$i=$ current readout from the electrode, $\mathrm{A}$ or $\mu \mathrm{A}$

$i_{b}=$ current readout from the electrode at steady state which is $i_{s s}$ for the control datum and $i_{f}$ for the test datum in Eq. 20, A or $\mu \mathrm{A}$

$i_{f}=$ current readout from the electrode after the steady state is attained after a specific dose of a toxic chemical is added to the test medium, $\mathrm{A}$ or $\mu \mathrm{A}$

$i_{k}=$ current readout from the electrode after steady state is attained with a nonviable biofilm, $\mathrm{A}$ or $\mu \mathrm{A}$

$i_{S}=$ current readout from the electrode when the aqueous solution is air-saturated, $\mathrm{A}$ or $\mu \mathrm{A}$

$i_{s s}=$ current readout from the electrode after steady state is attained before toxic chemical is added to the test medium, A or $\mu \mathrm{A}$

$k$ = maximum specific or cellular $\mathrm{O}_{2}$ utilization (consumption) rate via cell respiration per unit volume, $\mathrm{mg} /(\mathrm{L} \cdot \mathrm{s} \cdot$ cell $)$

$k_{o}=k$ computed from Eq. 20 (flux continuity at the filter pad/cell layer interface in Eq. 11$), \mathrm{mg} /(\mathrm{L} \cdot \mathrm{s}$ - cell $)$

$k_{1}=k$ computed from Eq. 25 (one-layer model), $\mathrm{mg} /(\mathrm{L} \cdot \mathrm{s} \cdot$ cell)

$k_{3}=k$ computed from Eq. 19 (three-layer model), $\mathrm{mg} /(\mathrm{L} \cdot \mathrm{s} \cdot$ cell)

$K_{S}=$ Monod constant $=\mathrm{O}_{2}$ concentration at which respiration rate per unit volume is half the maximum $\mathrm{O}_{2}$ consumption rate $(k N), \mathrm{mg} / \mathrm{L}$ or $\mathrm{mol} / \mathrm{cm}^{3}$

$\delta=$ thickness of boundary layer, $\mathrm{cm}$ or $\mu \mathrm{m}$

$L_{c}=$ thickness of cell layer, $\mathrm{cm}$ or $\mu \mathrm{m}$

$L_{f}=$ thickness of filter pad, $\mathrm{cm}$ or $\mu \mathrm{m}$

$L_{p}=$ thickness of plastic membrane, $\mathrm{cm}$ or $\mu \mathrm{m}$

$n=$ number of equivalents per mole of $\mathrm{O}_{2}(n=4)$; sample size in the various analyses

$N=$ number of cells in the biofilm

$P_{m}=$ permeability of plastic membrane, $\mathrm{cm}^{2} / \mathrm{s}$

$R=$ generation rate of $\mathrm{O}_{2}$ per unit volume, $\mathrm{mg} /(\mathrm{L} \cdot \mathrm{min})$ or moles $/\left(\mathrm{cm}^{3} \cdot \mathrm{s}\right)$

$\mathrm{RCR}=$ respiratory control ratio $=$ ratio of a respiration parameter for the test to the control run, \%

$\mathrm{RCR}_{k}=$ respiratory control ratio based on the parameter $k$

$\mathrm{RCR}_{k N}=$ respiratory control ratio based on the parameter $k N$

$\mathrm{SD}=$ standard deviation

$t=$ time, $\mathrm{s}$ or $\min$

$t_{3}=t$-score in the paired $t$-test with 3 degrees of freedom $(n=4)$

$z=$ axial distance into biofilm away from the aqueous bulk solution (diffusion path), $\mathrm{cm}$ or $\mu \mathrm{m}$

\section{Greek letters}

$\delta=$ thickness of boundary layer, $\mathrm{cm}$ or $\mu \mathrm{m}$

$\phi=$ electrode sensitivity coefficient $=i_{S} / C_{S}, \mu \mathrm{A} /(\mathrm{mg} / \mathrm{L})$

\section{Subscripts}

$b=$ cell layer $/$ plastic membrane interface

$B L=$ boundary layer

$C=$ cell layer

$f=$ filter pad; final current reading after addition of toxic chemical

$f 1=$ boundary layer/filter pad interface

$f 2=$ filter $\mathrm{pad} /$ cell layer interface

$k=$ conditions after total inhibition of cell respiration

$m=$ plastic membrane

$M=$ Monod equation

$S=$ air-saturation conditions 
$s s$ = final steady-state current before toxic chemical is added

$W=$ water (aqueous conditions apply in the boundary layer)

$o=$ based on boundary condition concerning flux continuity at the filter pad/cell layer interface

$1=$ based on one layer model

3 = based on three layer model

\section{Literature Cited}

Benefield, L., and F. Molz, "Mathematical Simulation of a Biofilm Process," Biotechnol. and Bioeng., 27,921 (1985).

Bird, R. B., W. E. Stewart, and E. N. Lightfoot, Transport Phenomena, Wiley, New York, 515 (1960).

Davis, G., "Advances in Biomedical Sensor Technology: a Review of the 1985 Patent Literature," Biosensors, 2, 101 (1986).

Goldblum, D. K., "Biofilm Electrode for Screening of Toxic Chemicals: Electrode System Characterization," PhD Thesis, Chemical Engineering and Environmental Heaith Science, University of Michigan (1988).

Haubenstricker, M. E., "Development of a Toxicity Biosensor Based on Changes in Mitochondrial Respiration Rates," PhD Thesis, Environmental Health Science, University of Michigan (1984).

Hitchman, M. L., "Measurement of Dissolved Oxygen," Chemical Analysis, 49, P. J. Elving, J. D. Winefordner, and I. M. Kolthoff, eds., Wiley, New York (1978)

Holodnick, S. E., "The Biofilm Electrode Sensor System for Acute Toxicity and Viral Screening," PhD Thesis, Environmental Health Science, University of Michigan (1988).

Kornegay, B. H., and J. F. Andrews, "Kinetics of Fixed-Film Biologica!
Reactors," J. Water Pollution Control Federation, 40(11), Part 2. R460 (1968).

Lehninger, A. L., Biochemistry, 2nd ed., Worth Publishers, New York, $519,611(1975)$

Li, X. M. B.S. Liang, and H. Y. Wang, "Computer Aided Analysis for Biosensing and Screening," Biotechnol and Bioeng., 31, 250 (1988).

Liang, B. S., X. M. Li, and H. Y. Wang, "Cellular Electrode for Antitumor Drug Screening," Biotechnol. Prog., 2(4), 187 (1986).

Lowe, C. R., "An Introduction to the Concepts and Technology of Biosensors." Biosensors, 1, 3 (1985).

Mancy. K. H., "Development and Application of Biosensors in Pollution Control Programs," Int. Symp. Electrochemical Sensors, Rome, Italy (June 12-14, 1984).

Mancy, K. H., D. A. Okun, and C. N. Reilley, "A Galvanic Cell Oxygen Analyzer," J. Electroanal. Chem., 4, 65 (1962).

Parulekar, S. J., G. B. Semones, M. J. Rolf, J. C. Lievense, and H. C. Lim, "Induction and Elimination of Oscillations in Continuous Cultures of Saccharomyces Cerevisiae," Biotechnol. and Bioeng., 28,700 (1986).

Perry, R. H., and C. H. Chilton, Chemical Engineers' Handbook, 5th ed., McGraw-Hill, New York, 3-225 (1973).

Reid, R. C., J. M. Prausnitz, and T. K. Sherwood, The Properties of Gases and Liquids, 3rd ed., McGraw-Hill, New York, 567 (1977).

Rittman, B. E., and P. L. McCarty, "Model of Steady-State-Biofilm Kinetics," Biotechnol and Bioeng., 22, 2343 (1980).

-_- "Evaluation of Steady-State-Biofilm Kinetics," Biotechnol. and Bioeng.. 22, 2359 (1980).

Manuscript received Nov. 7. 1988, and revision received Nov. 2. 1989. 